\title{
EL HOSPITAL DE SAN JOSÉ Ochenta años atrás... Ochenta años después
}

Laima Didziulis G. MD. *

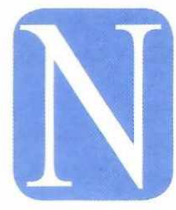

o cabe la menor duda que la creación de la Sociedad de Cirugía de Bogotá y la fundación del hospital, fueron acontecimientos que en su momento marcaron una época en el desarrollo social y cultural de la ciudad, dejando una huella imborrable en la formación de muchas generaciones en las que se destacan figuras reconocidas como hombres de ciencia en el campo de la medicina y cirugía, que más allá de la aplicación de diversas técnicas han velado a través de los tiempos por encontrar respuestas a las dolencias de los pacientes.

La templanza y el espíritu emprendedor de los fundadores de la Sociedad de Cirugía hicieron que en sus inicios la formación de profesionales de algunas escuelas de medicina tuvieran como escenario de práctica las instalaciones del Hospital de San José. La iniciativa de las siguientes generaciones en un transcurrir académico y de servicio, llevaron a la creación de la Fundación Universitaria de Ciencias de la Salud, aportando a la sociedad prestantes profesionales de las diversas áreas de la salud.

Transcurridos ochenta años desde que el Hospital de San José abrió sus puertas el 8 de febrero de 1925 , su buen nombre y reputación se extienden mas allá de las fronteras patrias dando testimonio de la dedicación y del coraje de todos aquellos que han contribuido a su creación y desarrollo.

Con el devenir de los tiempos y los grandes ajustes determinados por los sistemas económicos de cada época, el hospital ha encontrado con grandes esfuerzos las estrategias que lo han hecho permanecer en el tiempo, trabajando con esmero y dedicación en pro de enfermos y comunidades menos favorecidas.

* Editorialista invitada. Directora Médica Hospital de San José, Profesora

Titular Fundación Universitaria de Ciencias de la Salud.
El cambio drástico que determinó la puesta en marcha de la ley 100 de 1993, con un esquema de subsidio a la oferta, ha sido una de las pruebas más difíciles de soportar, exigiendo de todos y cada uno de los integrantes del hospital el mayor esfuerzo para la continuidad, permanencia y desarrollo del mismo, en un período caracterizado por la crisis del sector salud y el cierre de varias instituciones hospitalarias.

Es así como hoy podemos afirmar con orgullo que hemos dado la repuesta exigida por el sistema y que más allá de ello trabajamos día a día según un plan estratégico definido, logrando a partir del crecimiento personal y profesional optimizar los recursos y la atención en salud. Contamos con la retroalimentación valiosa y permanente de los diferentes programas de la Fundación Universitaria de Ciencias de la Salud, y de los numerosos grupos interdisciplinarios que conforman los comités amable, de ética y docencia entre otros, con el apoyo del área administrativa.

El hospital ha crecido mucho pero ha conservado esa filosofía del cuidado humanitario, ceñido al rigor científico y acorde con los avances tecnológicos del momento.

Para el futuro esperamos contribuir con el cuidado de los pacientes, basado en sus necesidades. Continuar con una tradición de formación de médicos y especialistas orgullo de nuestra institución por sus conocimientos, su ética y su trato humanitario, con la formación en los valores que profesamos en la institución y con la innovación tecnológica puesta al servicio de la investigación y del cuidado de la salud.

Así pretendemos cumplir con el legado de nuestros fundadores: "Curar algunas veces, aliviar otras, pero consolar siempre". 